\title{
Simulation of Flash-Flood-Producing Storm Events in Saudi Arabia Using the Weather Research and Forecasting Model*
}

\author{
LIPING DENG \\ Physical Sciences and Engineering Division, King Abdullah University of Science and Technology, Thuwal, Saudi Arabia \\ MATTHEW F. MCCABE \\ Water Desalination and Reuse Center, Biological and Environmental Sciences and Engineering Division, \\ King Abdullah University of Science and Technology, Thuwal, Saudi Arabia

\section{GEORGIY STENCHIKOV} \\ Physical Sciences and Engineering Division, King Abdullah University of Science and Technology, Thuwal, Saudi Arabia \\ JASON P. EVANS \\ Climate Change Research Centre, University of New South Wales, Sydney, New South Wales, Australia \\ PAUL A. KUCERA \\ Research Applications Laboratory, NCAR, Boulder, Colorado
}

(Manuscript received 8 July 2014, in final form 18 November 2014)

\begin{abstract}
The challenges of monitoring and forecasting flash-flood-producing storm events in data-sparse and arid regions are explored using the Weather Research and Forecasting (WRF) Model (version 3.5) in conjunction with a range of available satellite, in situ, and reanalysis data. Here, we focus on characterizing the initial synoptic features and examining the impact of model parameterization and resolution on the reproduction of a number of floodproducing rainfall events that occurred over the western Saudi Arabian city of Jeddah. Analysis from the European Centre for Medium-Range Weather Forecasts (ECMWF) interim reanalysis (ERA-Interim) data suggests that mesoscale convective systems associated with strong moisture convergence ahead of a trough were the major initial features for the occurrence of these intense rain events. The WRF Model was able to simulate the heavy rainfall, with driving convective processes well characterized by a high-resolution cloud-resolving model. The use of higher $(1 \mathrm{~km}$ vs $5 \mathrm{~km})$ resolution along the Jeddah coastline favors the simulation of local convective systems and adds value to the simulation of heavy rainfall, especially for deep-convection-related extreme values. At the 5-km resolution, corresponding to an intermediate study domain, simulation without a cumulus scheme led to the formation of deeper convective systems and enhanced rainfall around Jeddah, illustrating the need for careful model scheme selection in this transition resolution. In analysis of multiple nested WRF simulations $(25,5$, and $1 \mathrm{~km})$, localized volume and intensity of heavy rainfall together with the duration of rainstorms within the Jeddah catchment area were captured reasonably well, although there was evidence of some displacements of rainstorm events.
\end{abstract}

\footnotetext{
* Supplemental information related to this paper is available at the Journals Online website: http://dx.doi.org/10.1175/JHM-D-140126.s1.
}

Corresponding author address: Liping Deng, Physical Sciences and Engineering Division, King Abdullah University of Science and Technology, PSE G3409, Thuwal 99354, Saudi Arabia. E-mail: liping.deng@kaust.edu.sa

\section{Introduction}

Counterintuitively, flash-flood-type events are a natural phenomenon of many arid zone systems (e.g., Haggag and El-Badry 2013). In arid environments, precipitation can arrive in short and intense rainfall bursts. These events, when combined with dry and sometimes infiltrationlimited soils that can form as a result of surface armoring (e.g., Al Saud 2010) and other geomorphological features, 
can translate directly into fast-flowing surface runoff. The ephemeral arterial dry river systems that dominate such environments, commonly referred to as arroyos, wadis, or nullahs, are often characterized by their locations in narrow mountainous and steep-sided terrain, which results in rapid channeling of incident rainfall flows. The flooding risk to downstream settlements is generally difficult to manage, especially as hydrological (and hydraulic) infrastructure in such areas is often lacking.

Jeddah, the second largest city in Saudi Arabia, has suffered from a number of flash-flood events over the last decade. The surface topography in the area around Jeddah increases from west to east, with high mountains on the eastern side. These mountains act as a natural barrier to passing convective storms, resulting in large rainfall bursts that occur in a short time period and flow from the foothills of these slopes directly into the city. The factors that influence such convective systems include cyclone development over the Mediterranean and anticyclone development over the Arabian Peninsula (e.g., De Vries et al. 2013; El Kenawy et al. 2014), warm sea surface temperatures of the Red Sea, high atmospheric moisture content, and the local topography.

In recent years, one of these storms resulted in more than 100 fatalities and an economic loss estimated to be in excess of 900 million U.S. dollars (USD) (see Emergency Events Database at www.emdat.be). A single rain event in November 2009 caused an observed rainfall depth of approximately $140 \mathrm{~mm}$ at King Abdulaziz International Airport in Jeddah and resulted from a quasi-stationary mesoscale convective system that lasted around $8 \mathrm{~h}$ (Haggag and El-Badry 2013). This is particularly notable, as the average total annual rainfall of the region is $53.5 \mathrm{~mm}$.

Modeling of flash-flood events in arid environments that result from these extreme events is a difficult but important task. The challenge is often related to adequately describing the precursor intense rainfall that causes the flood response, as such rainfall is generally poorly simulated and forecasted. Many approaches are employed to deal with this problem, such as ensemble means of multimodels, higher-resolution downscaling, improvement of the representation of physical processes, and inclusion of hydrological processes affected by the surface temperature (e.g., evapotranspiration). The use of downscaling approaches that provide for a more realistic simulation of complex topography and subgrid systems (e.g., Evans and McCabe 2013) has been shown to be useful in characterizing the observed amount and intensity of precipitation. For example, using simulation comparisons of the $12-\mathrm{km}$ Weather Research and Forecasting (WRF) Model with the 36-km WRF and the 25-km Hadley Centre Regional
Climate Model (HadRM), Zhang et al. (2009) identified an improvement in capturing precipitation with the use of a finer grid spacing. They also found that the accurate simulation of the magnitude and distribution of precipitation was strongly tied to the interactions between airflow and local topography. Heikkilä et al. (2011) suggested that the better representation of the local topography in WRF due to resolution increases from 30 to $10 \mathrm{~km}$ contributed to an improved simulation of extreme precipitation. Likewise, Cardoso et al. (2013) demonstrated improved simulations of precipitation fields in the Iberian Peninsula by comparing two WRF resolutions ( 9 vs $27 \mathrm{~km}$ ). On the other hand, Almazroui (2011) used a regional climate model (RCM) with different resolutions $(25-50 \mathrm{~km})$ and found that the higher resolution did not always guarantee improvements in the simulation of intense rainfall events over the Arabian Peninsula. Kopparla et al. (2013) also identified some cases that used higher resolution $\left(0.25^{\circ}\right.$ vs $1^{\circ}$ and $2^{\circ}$ ) with no significant enhancement in the precipitation simulation using the Community Earth System Model, version 1.

While the results above focused on resolutions coarser than $9 \mathrm{~km}$, rainfall simulations at even finer scales (e.g., less than $5 \mathrm{~km}$ ) have increasingly become a research and operational target, especially for the water resource community. Anquetin et al. (2005) studied a devastating flood that occurred in France using two types of meteorological simulations and suggested that an increase of grid resolution to $3 \mathrm{~km}$ or even higher would lead to larger precipitation amounts with explicitly resolved convection in the hydrostatic model. Davolio et al. (2009) used a number of cloud-resolving models (e.g., 2.5-4-km resolution in WRF and MM5) to simulate a flash flood near Venice and suggested that the interaction of largescale features with the local topography is important for severe precipitation forecasting. Xie and Zhang (2012) used a high-resolution WRF simulation $(4.5 \mathrm{~km})$ to examine heavy rainfall associated with Typhoon Morakot and identified that the interaction between the complex topography and the typhoon-related circulation played a dominant role in simulating the heavy rainfall, especially in regard to the intensity and location. Gao and Sui (2013) also examined extreme rainfall simulations using the cloud-resolving WRF Model with a 4-km-resolution inner domain and found that the dynamic downscaling approach favors the extreme precipitation simulation over the western North Pacific. Using MM5, Haggag and El-Badry (2013) described the flash flood of 25 November 2009 that occurred in Jeddah using a 1-km-resolution inner domain and highlighted the impact of the local topography (e.g., the Al Hejaz escarpment) on the upslope winds and upper tropospheric instability. From 
these and related investigations, it seems clear that convection-permitting resolutions and the related representation of the local topography are desirable in simulating heavy rainfall associated with flash-flood events.

To explore this line of investigation further, the research presented here focuses on examining the initial physical mechanisms responsible for three recent flash floods in Jeddah, occurring on 25-26 November 2009, 29-30 December 2010, and 14-15 January 2011. In particular, we investigate the feasibility of using WRF (version 3.5) at increasingly finer resolutions to achieve a more realistic simulation of these flood-producing rainfall events by evaluating model output against available observations. The overall aim of the study is not only to present a fundamental understanding of the hydrometeorology of these events, but also to explore the possibility of providing advanced warning of flashflood-producing storm systems (e.g., Cools et al. 2012). By analyzing, simulating, and characterizing these types of short-duration, high-intensity rainfall events across the Jeddah region, we aim at a better understanding to help guide decisions not only related to water resource storage and planning issues, but also regarding emergency management and response.

\section{Initial synoptic features for Jeddah floods}

The previous analyses of Haggag and El-Badry (2013) and De Vries et al. (2013) provide a comprehensive profile of Jeddah's flash floods, especially for the case on 25 November 2009. The rain event resulted mainly from a short quasi-stationary mesoscale convective system, with one rain gauge reporting more than $140 \mathrm{~mm}$ of rainfall in less than $8 \mathrm{~h}$ in Jeddah. Expanding upon these previous descriptions, a detailed review focusing on the initial synoptic features of the three Jeddah flash floods is presented in order to increase our understanding of the dominant mechanisms and antecedent conditions initiating these events. In this analysis, the European Centre for MediumRange Weather Forecasts (ECMWF) interim reanalysis (ERA-Interim; hereafter, ERA-I) dataset (Dee et al. 2011) is used to characterize all three rainstorms, with key hydrometeorological variables describing the precursor conditions of the flash-flood events presented in Fig. 1. The individual events are referred to here as case 1 (25 November 2009), case 2 (30 December 2010), and case 3 (14 January 2011). In all cases, the rainstorms lasted between 6 and $8 \mathrm{~h}$, and for cases 1 and 2 the rainstorms started around 0600 UTC, while case 3 occurred around 1800 UTC.

The geopotential height and wind vector maps at 850 (Figs. 1a,d,g) and $700 \mathrm{hPa}$ (see Fig. S1 in the supplemental materials; hereafter, an "S" precedes the figure number for figures that are in the supplemental materials) demonstrate for all three cases a cyclone between two anticyclones, located over the northern portion of the Red Sea. The cyclone is suggested as an extension of the Sudan low pressure zone moving from the west to the east in Haggag and El-Badry (2013), and the anticyclonic circulation on the right is stationary over the Arabian Peninsula during the whole process. A trough, which can be easily identified in the lower-to-middle troposphere along the Red Sea coast using the 850(Figs. 1a,d,g), 700-, and 500-hPa (see Figs. S1, S4) maps, is explored in a number of previous studies (e.g., Alpert et al. 2004; Tsvieli and Zangvil 2005; De Vries et al. 2013) and plays a critical role in the generation of the Jeddah floods. Additionally, before the trough, there is a low-level jet zone extending from the Red Sea coast to the inland around Jeddah (e.g., Fig. 1h), which in general leads to the movement of convective systems from west to east and has an important impact on the moisture source for the heavy rainfall (e.g., Xie and Zhang 2012; Al-Khalaf and Basset 2013).

The total column water vapor indicates the vertically integrated total precipitable water from the ground to the top of the atmosphere. In the total column water vapor plots (Figs. 1c,f,i) and the $850-\mathrm{hPa}$ specific humidity plots (Figs. 1b,e,h), a deep moist layer extends over the Jeddah area. This moisture comes from the direction of the Red Sea following the low-level jet from the southwest in all three cases. Also, the specific humidity maximum around Jeddah associated with the total column water vapor peak zone, as shown in Figs. 1b, 1c, 1e, 1f, 1h, and 1i, may be supported by a strong convergence zone (e.g., Almazroui 2011). In the wind vector fields (Figs. 1b,c,e,f,h,i), especially the 10-m wind map (Figs. 1c,f,i), a westerly-northwesterly wind flow crossing the Red Sea meets a southeasterly wind flow, generating a strong convergence zone around the Jeddah area, which is consistent with the local mesoscale convective systems ahead of the trough. The 2-m temperature plots (Figs. 1c,f,i) and 850-hPa temperature plots (see Fig. S3) suggest a warm Red Sea, which is identified as a factor in the generation of mesoscale convective systems in Haggag and El-Badry (2013).

As can be seen from the above analysis, all three cases indicate that the large-scale forcing associated with the deep trough along the Red Sea plays a key role in the timing and intensity of the Jeddah rainstorms by pushing the moist air from the Red Sea coast to the inland mountains. The corresponding moisture convergence and transport lead to heavy rainfall through local mesoscale convective systems, and the rainfall is directed 


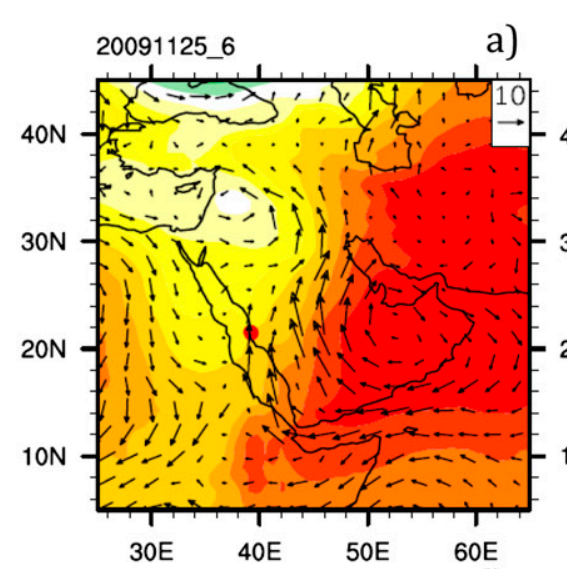

a)

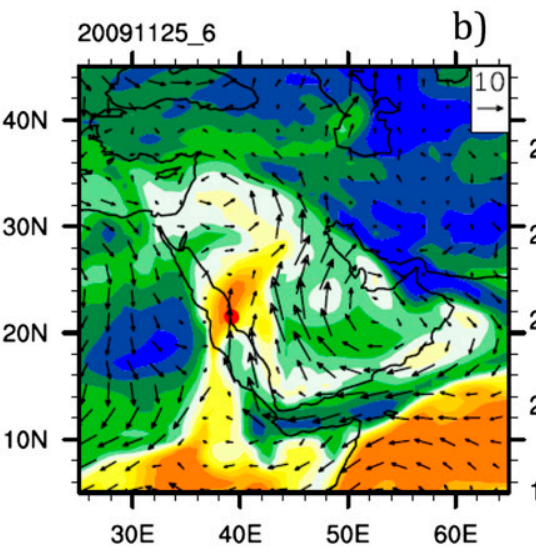

b)

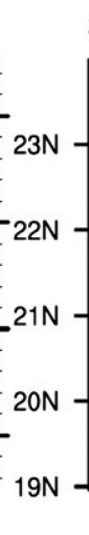

20091125_6

c)
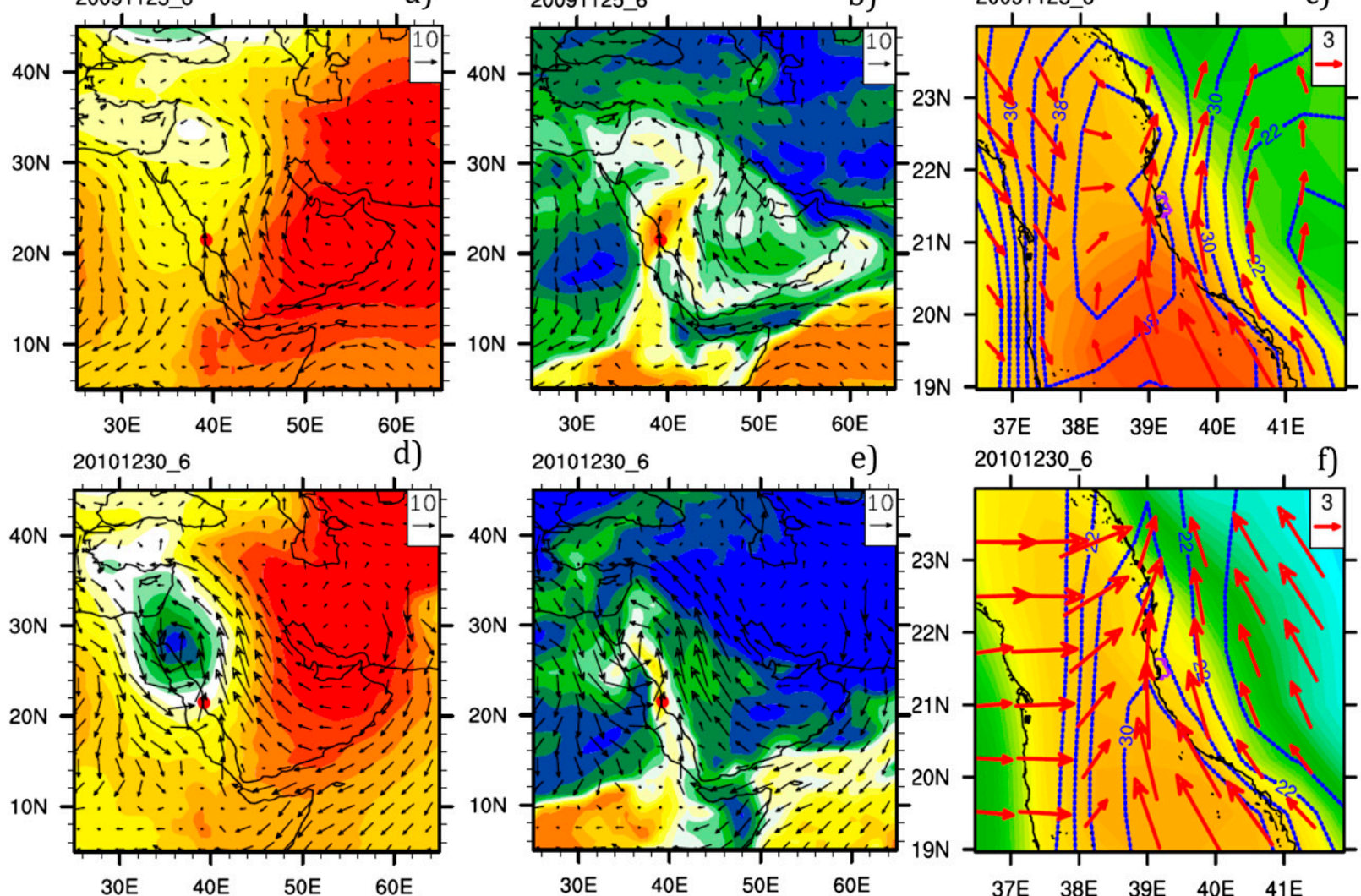

d)

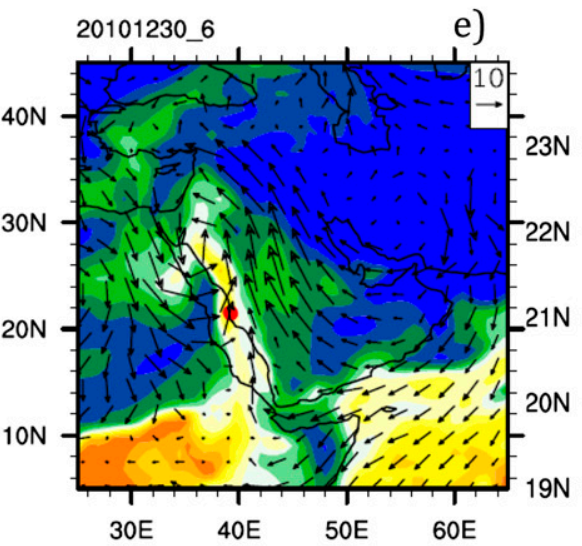

201012306
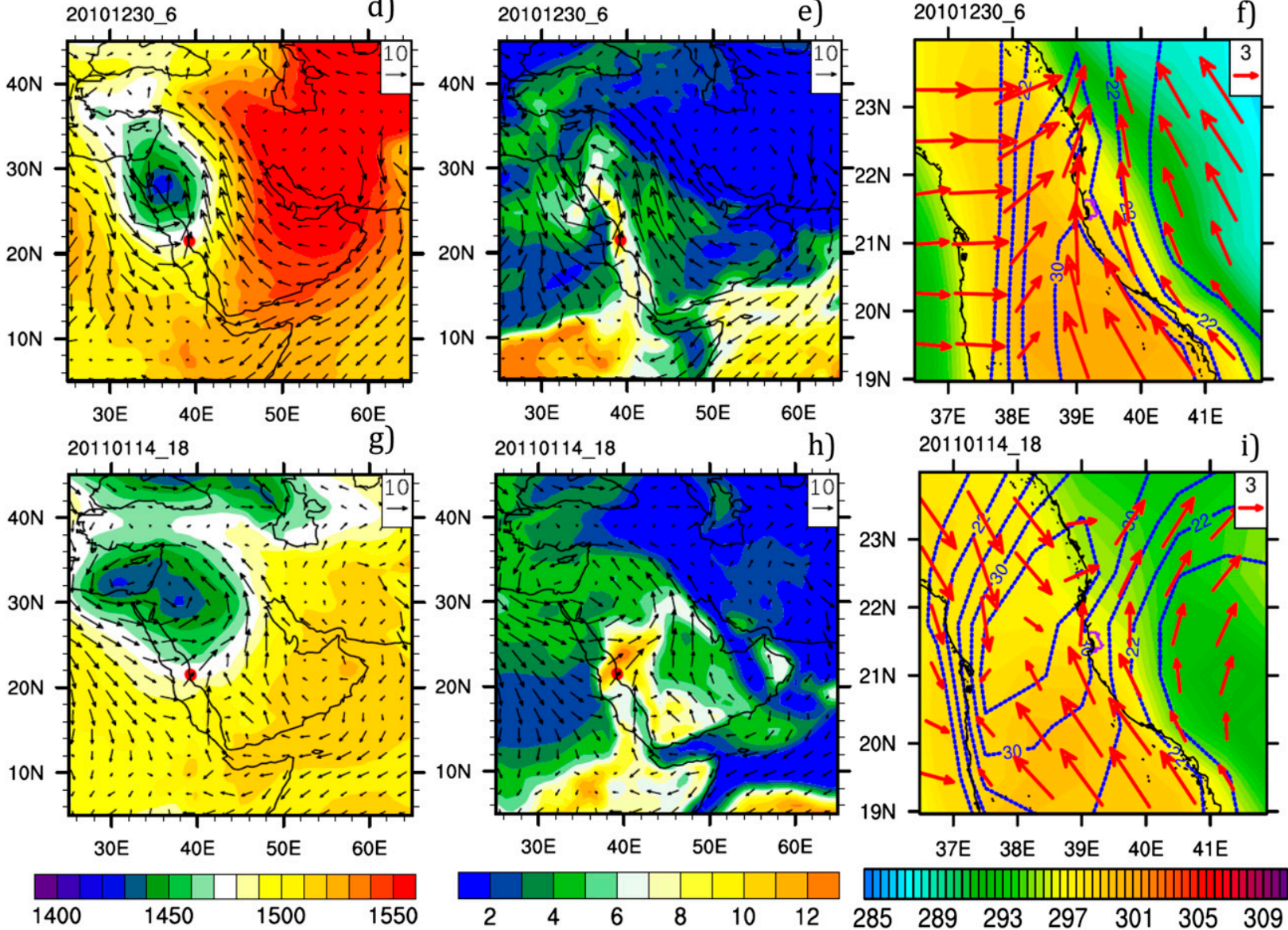

FIG. 1. (left) The $850-\mathrm{hPa}$ wind vectors $\left(\mathrm{m} \mathrm{s}^{-1}\right)$ and geopotential height (m; color shading); (middle) 850 -hPa wind vectors ( $\left.\mathrm{m} \mathrm{s}^{-1}\right)$ and specific humidity $\left(\mathrm{g} \mathrm{kg}^{-1}\right.$; color shading); and (right) 10-m wind vectors $\left(\mathrm{m} \mathrm{s}^{-1}\right), 2-\mathrm{m}$ temperature (K; color shading), and total column water vapor (mm; blue contours) for (a)-(c) case 1 (0600 UTC 25 Nov 2009), (d)-(f) case 2 (0600 UTC 30 Dec 2010), and (g)-(i) case 3 (1800 UTC 14 Jan 2011). The red dot in (left) and (middle) and the purple circle in the (right) indicate Jeddah.

back toward Jeddah city in a short time period by the mountain topography on the east side of Jeddah. The schematic presented in Fig. 2 illustrates the main initial synoptic features based on the three cases of flash-floodproducing rainstorms, consisting of 1) two anticyclones (indicated by an " $\mathrm{H}$ ") separated by a cyclone (indicated by an "L") and a trough, 2) a low-level jet zone ahead of the trough, 3) a strong moist tongue covering the Jeddah area, and 4) a strong convergence zone around Jeddah. These synoptic features in conjunction with the local 


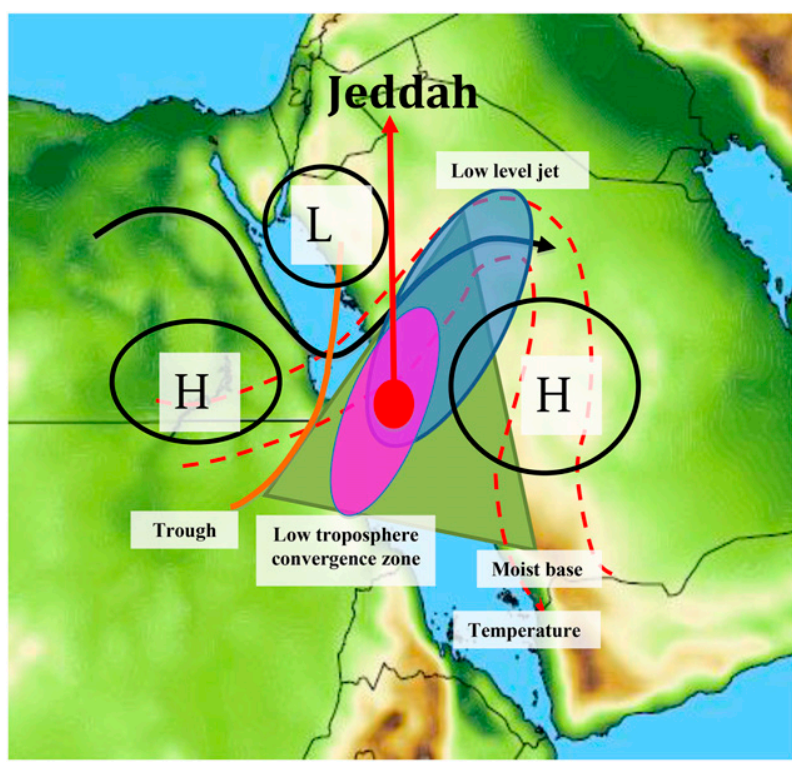

FIG. 2. Schematic plot of initial synoptic features for all three cases. "H" refers to anticyclone and " $\mathrm{L}$ " refers to the cyclone. The red dot indicates Jeddah. The figure also represents the trough (brown line), temperature (red dashed line), low tropospheric convergence zone (purple oval), low-level jet (blue oval), and moisture base (large green triangle under the overlapped purple and blue ovals).

topography lead to the Jeddah flash floods and can be considered as the key elements for effective forecasting of future flash floods in Jeddah.

\section{Model configurations and observation datasets}

\section{a. Model configurations}

Three unique flash-flood-producing events have been simulated by the nonhydrostatic WRF Model (version $3.5)$ in the convection-permitting mode. The WRF configuration consisted of a 1-km-resolution domain (D3) one-way nested within coarser domains (D2 at $5 \mathrm{~km}$ and D1 at $25 \mathrm{~km}$ ), as shown in Fig. 3. All simulations are driven by 6-hourly ERA-I forcing and with spectral nudging in the upper troposphere (above $500 \mathrm{hPa}$ ) employed over the outer domain. The use of spectral nudging was implemented to reduce the impact of the domain design while retaining large-scale features (Miguez-Macho et al. 2004). The high-resolution inner domain (D3) covers the Jeddah area with $256 \times 176$ grid points in the horizontal and 50 vertical levels. The simulation period is $48 \mathrm{~h}$ for each case, starting from $0000 \mathrm{UTC}$ and at least $12 \mathrm{~h}$ ahead of the initial time of each rainstorm. The model generates hourly output with a simulation time step of $30 \mathrm{~s}$.

An important aspect of this work was to identify a suitable model configuration to enable a reasonable

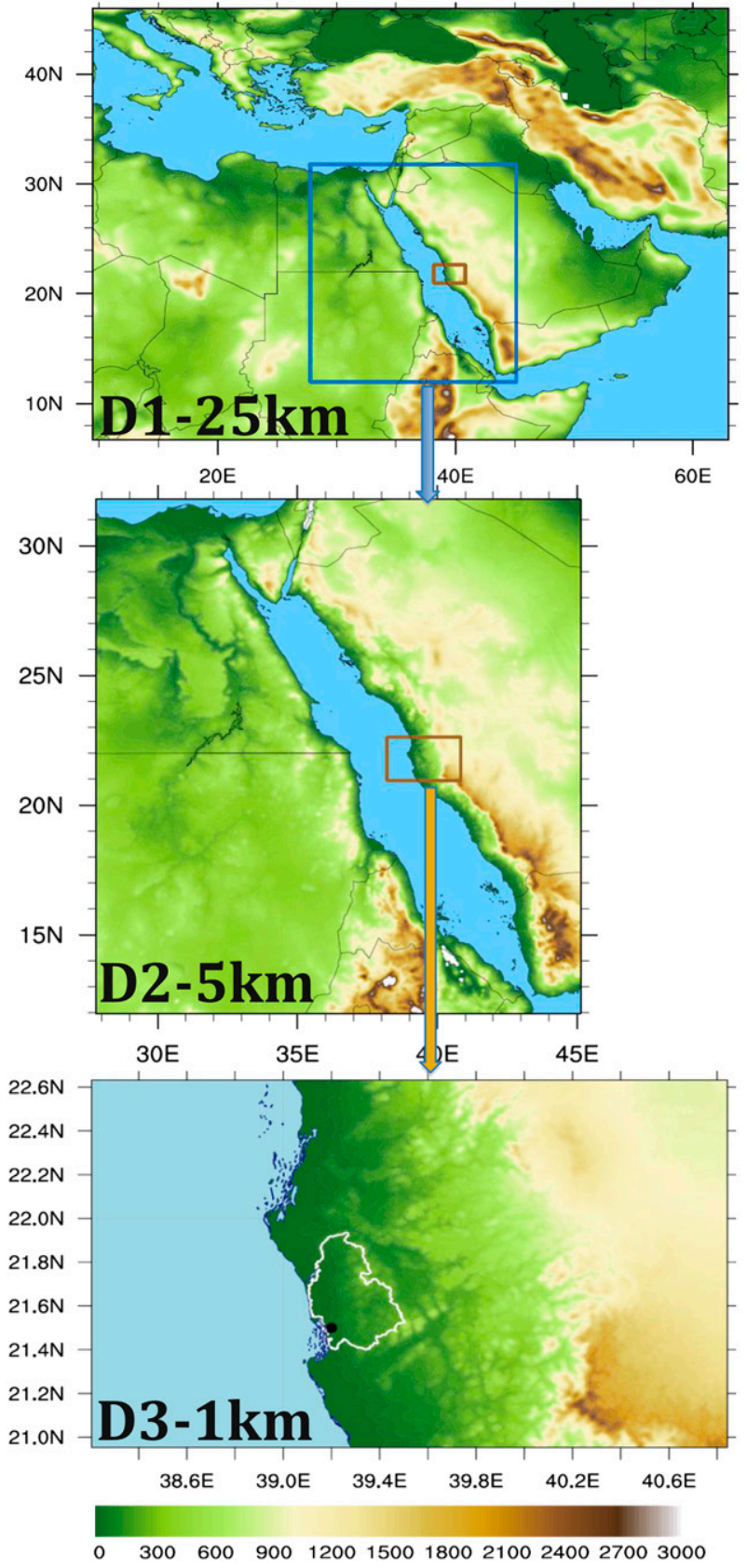

FIG. 3. Topographic plots $(\mathrm{m})$ for D1 $(208 \times 176$ points), D2 $(336 \times 416$ points $)$, and D3 $(256 \times 176$ points $)$. In the (bottom), the white line indicates the Jeddah catchment and the black dot is for Jeddah station.

simulation of the observed events. Table 1 reviews the model physics schemes that were employed in the simulation of these flash-flood events. The Lin cloud microphysics scheme (Lin et al. 1983; Rutledge and Hobbs 1984) was used for the coarse resolution in domain 1 and Eta (Ferrier) microphysics was used for fine resolution in domains 2 and 3. The Rapid Radiative Transfer 
TABLE 1. Description of the WRF physics configurations used in the model simulations.

\begin{tabular}{ll}
\hline \hline \multicolumn{1}{c}{ Physics } & \multicolumn{1}{c}{ Option } \\
\hline mp_physics & 2/5 (Lin/Eta; Lin et al. 1983) \\
ra_lw_physics & 4 (RRTMG; Iacono et al. 2008) \\
ra_sw_physics & 4 (RRTMG; Iacono et al. 2008) \\
sf_sfclay_physics & 2(Janjić Eta; Janjić 2001) \\
sf_surface_physics & 2(Noah; Tewari et al. 2004) \\
bl_pbl_physics & 2(MYJ; Janjić 1994) \\
\hline
\end{tabular}

Model for GCMs (RRTMG) was used to simulate the longwave and shortwave radiative transfer (Iacono et al. 2008). The Mellor-Yamada-Janjić (MYJ; Janjić 1994) boundary layer scheme was used, along with the Noah land surface model (Tewari et al. 2004). The surface fluxes used in the simulations were taken directly from the Noah land surface scheme using input from the Eta Monin-Obukhov surface layer parameterization (Janjić 2001). The Grell 3D cumulus convection scheme (Grell 1993; Grell and Devenyi 2002) was used in the coarse domain 1 only for the simulation discussed in sections $4 \mathrm{a}$ and $4 \mathrm{~b}$. Additionally, the sensitivity to cumulus scheme choice is discussed in section 4c, where both Grell 3D and Kain-Fritsch (Kain and Fritsch 1990; Kain 2004) schemes are used within the intermediate domain 2 (5-km resolution).

\section{b. Observation datasets}

As available observational datasets over the Arabian Peninsula generally do not have sufficient spatial and temporal coverage to enable robust evaluations, particularly for the rainfall data occurring along the Jeddah coast, a combination of three rainfall products were used to assess the WRF Model simulations. The first dataset is derived from the Tropical Rainfall Measuring Mission (TRMM) Multisatellite Precipitation Analysis (TMPA) rainfall product, which provides a moderate spatial $\left(0.25^{\circ} \times 0.25^{\circ}\right)$ and temporal (3 hourly) resolution (Huffman et al. 2007) for large-scale assessment. To provide higher-resolution evaluation of one of the storm events, a precipitation dataset $\left(0.02^{\circ} \times 0.02^{\circ} ; 5\right.$-min time interval) derived from reflectivity observations collected by a C-band Doppler located near the city of Taif, which is east of Jeddah (Kucera et al. 2010), was used to assess the simulations for the storm occurring between 24 and 26 November 2009 (case 1). Unfortunately, data from the Taif radar were not available for the other storm events. For all three cases, a quality-controlled set of daily rain gauge data observed from the Jeddah station $\left(21.5^{\circ} \mathrm{N}, 39.2^{\circ} \mathrm{E}\right)$ surface site was used as a principal source of in situ monitoring data. In addition, sounding datasets from the synoptic site located at King Abdulaziz International Airport in Jeddah $\left(21.7^{\circ} \mathrm{N}, 39.18^{\circ} \mathrm{E}\right)$ were available for the 2009 storm (case 1), providing vertical profiles of temperature, relative humidity, winds, and mixing ratio. These data are available from the University of Wyoming sounding data website (http://weather. uwyo.edu/upperair/sounding.html).

\section{Results}

In the following analyses, comparisons are made between point-scale (rain gauge) and grid-scale (satellite, radar, and model simulated) rainfall. While there are inevitable scale issues that affect the interpretation (and evaluation) of such data, the available information provides the best possible assessment of the model simulations, given the constraints and challenges of sourcing appropriate in situ datasets. Where possible, other evaluation metrics such as storm track, spatial extent, and timing are used to evaluate the storm simulations, reducing the need to focus solely on precipitation quantities.

\section{a. Evaluation of extreme values and evolution of storm events}

Figures $4 \mathrm{a}-\mathrm{c}$ show the 48 -h evolution of accumulated rainfall at Jeddah station for the three studied cases. The rain gauge accumulations in the plots are presented as constant values during each 24-h period, given their daily sampling resolution. In the TRMM and model output, the nearest grid point is used to compare with the rain gauge data. For case 1 (Fig. 4a), the rainfall from TRMM and radar data indicate approximately $15 \mathrm{~mm}$ of rainfall within $48 \mathrm{~h}$, whereas the simulated $1-\mathrm{km}$ resolution WRF output $(78 \mathrm{~mm})$ and the rain gauge data $(80 \mathrm{~mm})$ indicate good agreement in the total accumulation. However, the WRF simulated starting time of the rainstorm at Jeddah station has a 2-h lag compared with the TRMM and radar data. In case 2 (Fig. 4b), the WRF simulation $(52 \mathrm{~mm})$ also shows good agreement with the rain gauge 48 -h value $(52 \mathrm{~mm})$. The WRF simulated rainfall in case 3 (Fig. 4c) is approximately $53 \mathrm{~mm}$ and sits roughly between the TRMM $(103 \mathrm{~mm})$ and rain gauge data $(5 \mathrm{~mm})$. In general, the WRF simulations in Jeddah are comparable to the observations, especially for the rain gauge station observations.

To evaluate the simulation of atmospheric variables, vertical profile comparisons of temperature, potential temperature, relative humidity, and specific humidity monitored at King Abdulaziz International Airport and those derived from WRF Model outputs are presented in Figs. S5a-d for the 2009 event (case 1 at 1200 UTC 25 November 2009). In the plot, temperature profiles from the model and station match well (see Fig. S5a) and the potential temperature (see Fig. S5b) is increasing with height, which indicates that the stable feature of the atmosphere 


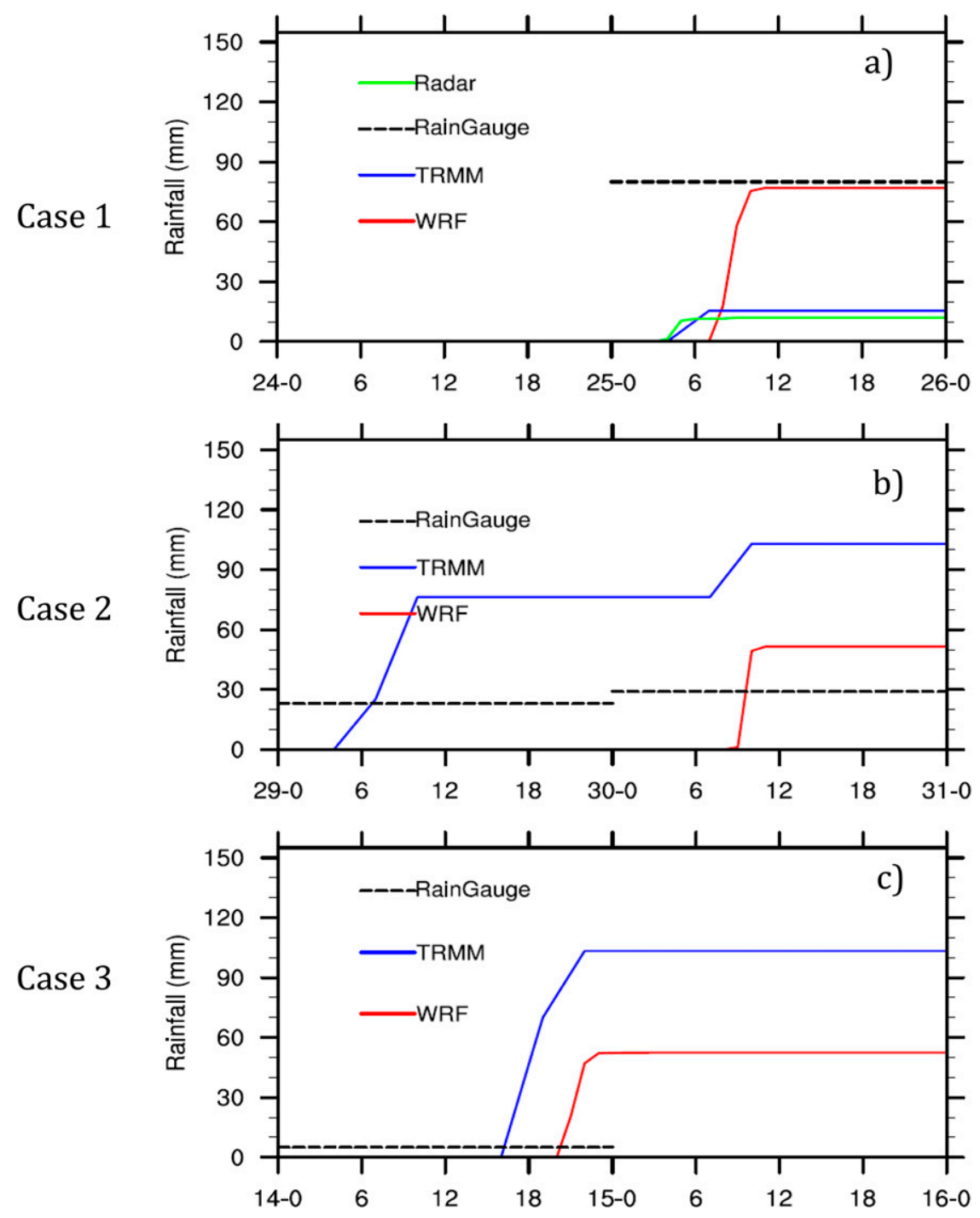

FIG. 4. Accumulated 48-h rainfall ( $\mathrm{mm}$ ) for (a) case 1 , (b) case 2 , and (c) case 3 at the Jeddah rain gauge station $\left(21.5^{\circ} \mathrm{N}, 39.2^{\circ} \mathrm{E}\right)$. The red line is the hourly WRF simulations, the blue line is the TRMM data, the black dashed line is the daily rain gauge data, and the green line is the Taif radar rainfall data.

after the case 1 rainstorm is simulated well in the WRF Model. Also, both the model and observations describe a moist low troposphere (around $850 \mathrm{hPa}$ ) via the specific and relative humidity profiles (see Figs. S5c,d).

Figure 5 shows the average rainfall for the Jeddah catchment area (see Fig. 3). The catchment represents a defined hydrologic regime derived from the Shuttle Radar Topography Mission (SRTM) 90-m digital elevation model and captures the mountainous region east of Jeddah. Further details and a description of the catchment can be found in Figs. 3 and 5 of Al Saud (2010). For case 1, the catchment-scale accumulated rainfall for the Jeddah region agrees well with that from the radar data ( $23 \mathrm{vs} 24.5 \mathrm{~mm}$ in Fig. 5a), although there is a 2-h lag for the rainfall occurrence period. This feature is also present in the hourly time evolution of rainfall (Fig. 5b), where the model effectively reproduces the observed rainfall peak, but with a time shift. The observed rainfall peak is around 0600 UTC, while the simulated peak is around 0800 UTC with a value similar to the observations ( 7.7 vs 7.0 and $9.2 \mathrm{~mm} \mathrm{~h}^{-1}$ ). For case 2 (Figs. 5c,d), a strong rainfall peak is observed in Fig. 5d $\left(33 \mathrm{~mm} \mathrm{~h}^{-1}\right)$, which matches the timing of second TRMM peak (0600-1200 UTC) but with a larger absolute value (33 vs $6.9 \mathrm{~mm} \mathrm{~h}^{-1}$ ). The peak rainfall time in case 3 (Fig. 5f) also matches the TRMM peak $\left(18.8 \mathrm{~mm} \mathrm{~h}^{-1}\right)$, but the value is smaller $\left(13.1 \mathrm{~mm} \mathrm{~h}^{-1}\right)$ and there is a $2-\mathrm{h}$ lag in the initiation of the event. In general, the rainfall 

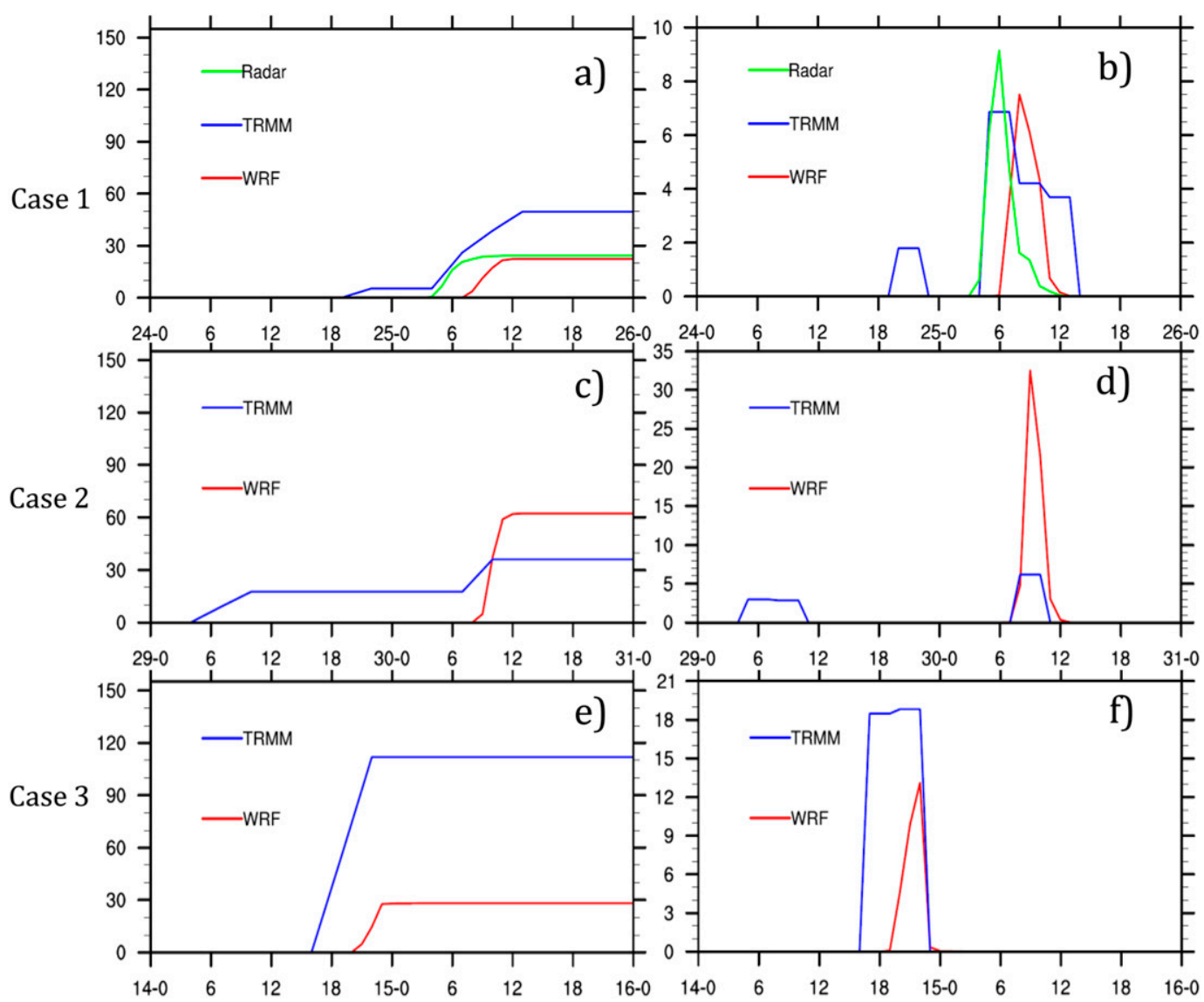

FIG. 5. (left) Accumulated 48-h rainfall (mm) and (right) precipitation rate $\left(\mathrm{mm} \mathrm{h}^{-1}\right)$ for (a),(b) case 1 , (c),(d) case 2, and (e),(f) case 3 averaged over the Jeddah catchment. The red line is for WRF simulations (D3), the blue line is for TRMM rainfall data, and the green line is for the Taif radar rainfall data.

peaks associated with the individual rain events are captured reasonably well for the Jeddah catchment, with some temporal shifts in either peak or storm initiation time for case 1 and case 3 .

Considering the complexity of atmospheric modeling and the challenges in obtaining reliable and accurate in situ data with which to evaluate such models, these simulations seem quite reasonable. The simulation of heavy rainfall associated with the flash-flood-producing rain event across the Jeddah catchment area is also evident in the hourly time (UTC) evolution of the storms. In Fig. 6 (left), an observed rainstorm from the in situ radar data for case 1 moves from the northwest to the southeast, passing over Jeddah with a peak rainfall rate larger than $14 \mathrm{~mm} \mathrm{~h}^{-1}$. Additionally, the rainstorm extends in a direction from the southwest to the northeast, perpendicular to the direction of movement of the storm center. The simulated case 1 (Fig. 6, right) shows similar features, with the rainstorm moving in the correct northwest-to-southeast direction and with similar intensity values, but with a displacement in the rainfall distributions and time. For example, starting at 0700 UTC 25 November, the rainstorm is located over downtown Jeddah in the model output (see Fig. 6, right), whereas it is east of the area in the observations (see Fig. 6, left). Reproducing the rainfall pattern and spatial distribution is a considerable challenge for models (e.g., Anquetin et al. 2005) and is affected by many factors such as the representation of physical processes and biases introduced through the initial and boundary conditions. Although there is a displacement in our simulation, the pattern correlation (see Evans and McCabe 2010) between observed and simulated rainstorms for case 1 based on hourly evolution is higher in the Jeddah area (correlation coefficient $>0.8$ ) compared with other regions, especially for the northeast of Jeddah (see Fig. S6). This high pattern correlation indicates that both the amplitude and phase of observed and simulated rainstorms are in better agreement over the northeast sector of the Jeddah region, where the topography is higher than the city of Jeddah and which favors the generation of convection and flash floods. Simulated cases 2 and 3 (see 

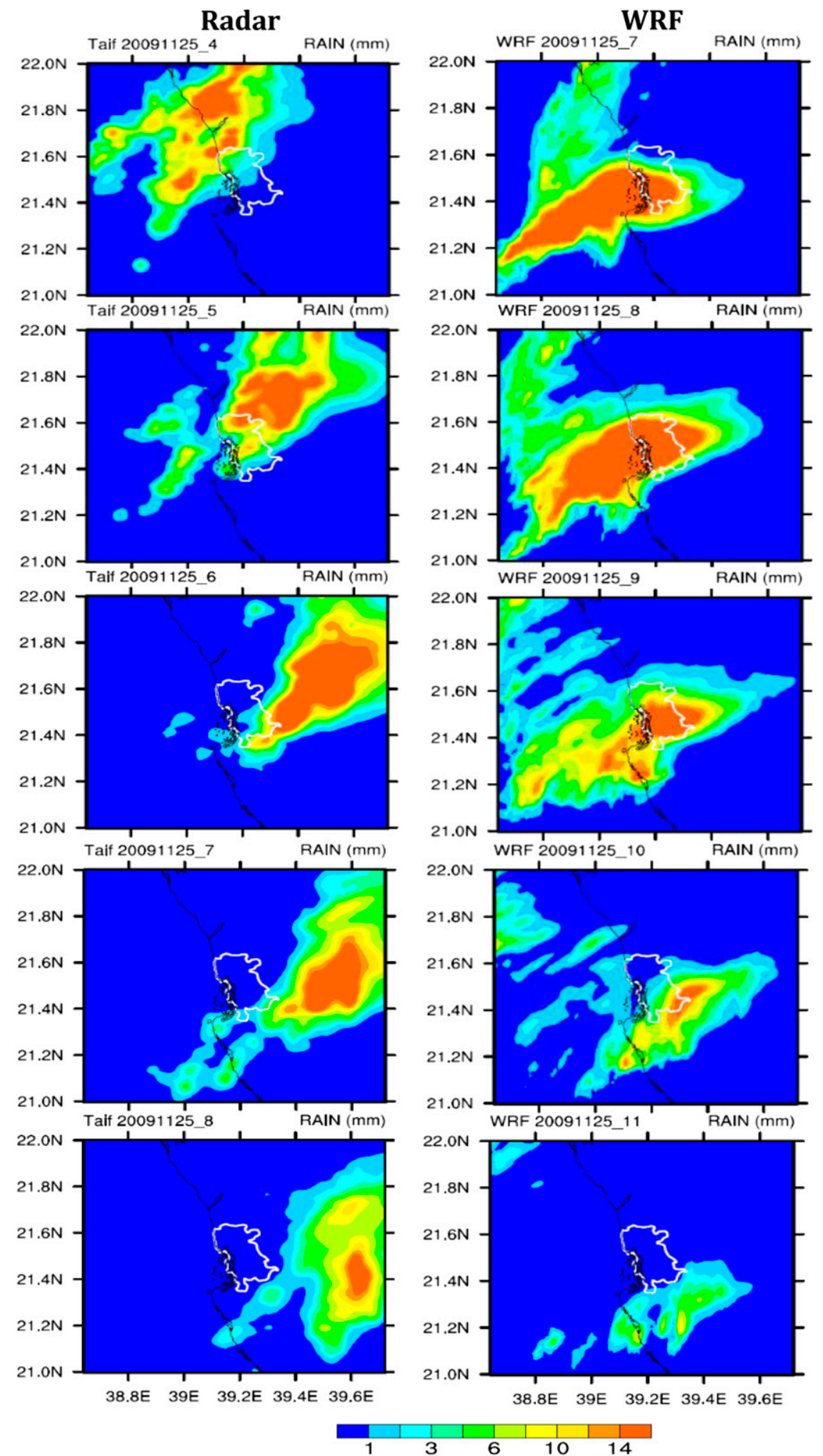

FIG. 6. Hourly time evolution of rainstorms ( $\mathrm{mm}$ ) for case 1 from (left) Taif radar data and (right) WRF D3. The white outline represents downtown Jeddah. 


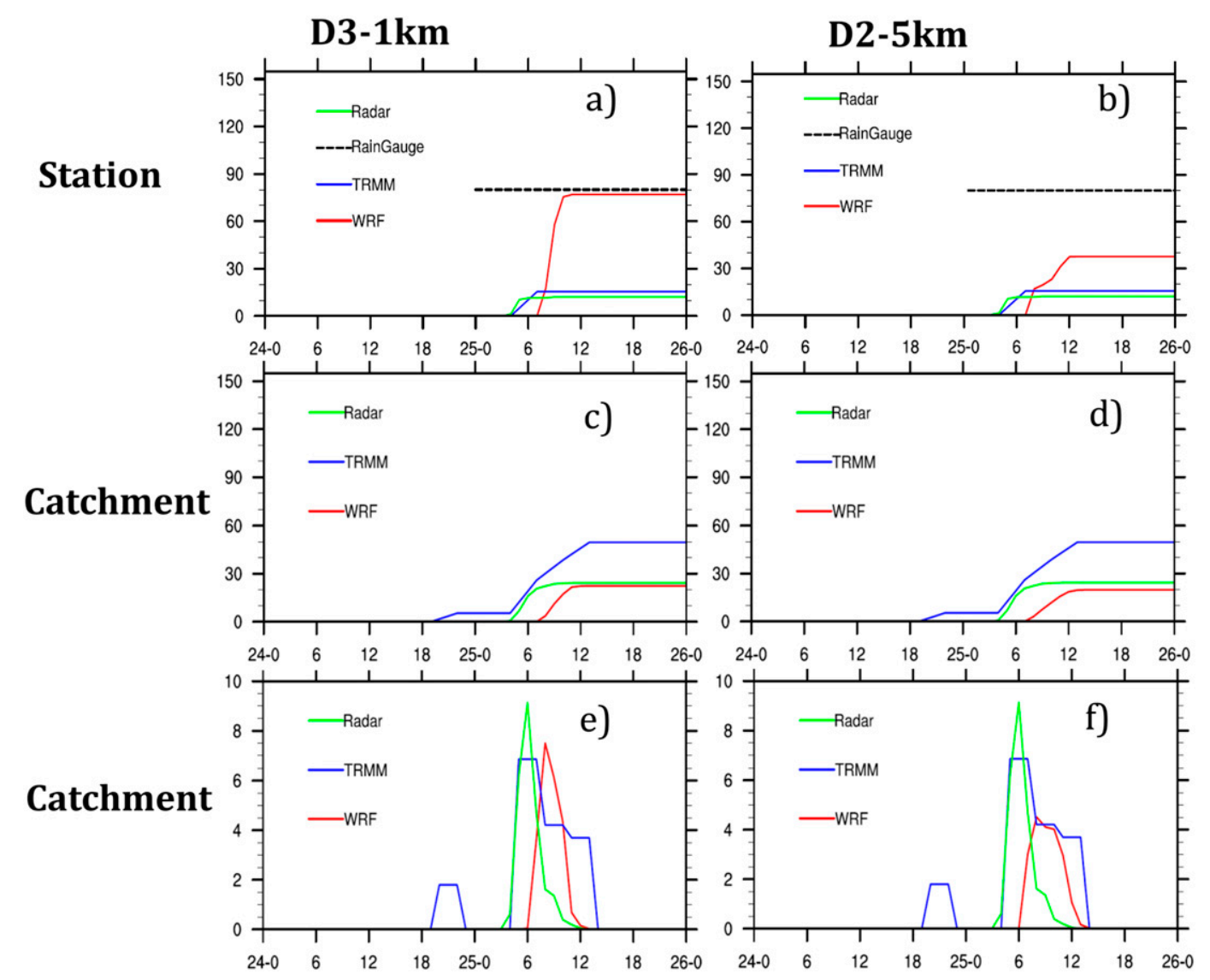

FIG. 7. (a),(b) Accumulated rainfall ( $\mathrm{mm}$ ) at Jeddah station, (c),(d) accumulated rainfall ( $\mathrm{mm}$ ) averaged over the Jeddah catchment, and (e),(f) precipitation rate $\left(\mathrm{mm} \mathrm{h}^{-1}\right)$ averaged over the Jeddah catchment from WRF (left) D3 and (right) D2 for case 1. The red line is for WRF simulations, the blue line is for TRMM rainfall data, the green line is for the Taif radar rainfall data, and the black line is for the daily rain gauge data.

Fig. S7) both reflect a moving rainstorm from the northwest to the southeast.

\section{b. Impact of model resolution on storm reproduction}

Although downscaling will not necessarily improve model simulations of heavy rainfall in all cases (e.g., Almazroui 2011), the Jeddah region has complex orographic and geographic features, such as a mountain range close to the city and a land-ocean boundary, that warrant model simulation improvements along with an increasing resolution (e.g., from 5 to $1 \mathrm{~km}$ ). Figure 7 shows the rainfall comparisons of results from D2 with 5$\mathrm{km}$ resolution and D3 with 1-km resolution. For case 1, at the Jeddah station (Figs. 7a,b), D3 shows a larger accumulated rainfall value $(78 \mathrm{~mm})$, which agrees better with the rain gauge data $(80 \mathrm{~mm})$ compared to the D2 prediction ( $38 \mathrm{~mm}$ in Fig. $7 \mathrm{~b}$ ). The accumulated rainfall value averaged over the Jeddah catchment in D3 is also larger than that in D2 (23 vs $20 \mathrm{~mm}$ in Figs. 7c,d), and there is a stronger rainfall peak around $7.5 \mathrm{~mm} \mathrm{~h}^{-1}$ in D3 (Fig. 7e) compared with $4.6 \mathrm{~mm} \mathrm{~h}^{-1}$ in D2 (Fig. 7f). In fact, this large value and strong peak in D3 agrees better with the observations compared to that in D2, as both radar and TRMM precipitation datasets show large accumulated rainfall values (e.g., $50 \mathrm{~mm}$ for TRMM in Fig. 7c) and strong rainfall peaks (e.g., $9.2 \mathrm{~mm} \mathrm{~h}^{-1}$ for radar data in Fig. 7e). For case 2 (see Figs. S8a-f), although the difference is small ( 51 vs $50.5 \mathrm{~mm}$ in Figs. S8a,b), the accumulated rainfall value is larger in D3 than that in D2 for Jeddah station and agrees better with the 48 -h rain gauge value $(52 \mathrm{~mm}$ in Fig. S8a). At the catchment scale, the accumulated rainfall value in D3 is still larger than that in D2 (61 vs $59 \mathrm{~mm}$ in Figs. S8c,d), and D3 has a larger rainfall peak value compared to that in D2 (32.7 vs $26 \mathrm{~mm} \mathrm{~h}^{-1}$ in Figs. S8e,f). Additionally, both D3 and D2 overestimate the rainfall (see Figs. S8e,f) in terms of the catchment average. For case 3 (see Figs. S8g-1), the accumulated rainfall value in D3 is larger than that in D2 (53 vs $28 \mathrm{~mm}$ in Figs. S8g,h) at Jeddah station and closer to the TRMM accumulated rainfall value of $103 \mathrm{~mm}$, while for the Jeddah catchment, the value of D3 is slightly less than that in D2 (28.5 vs 

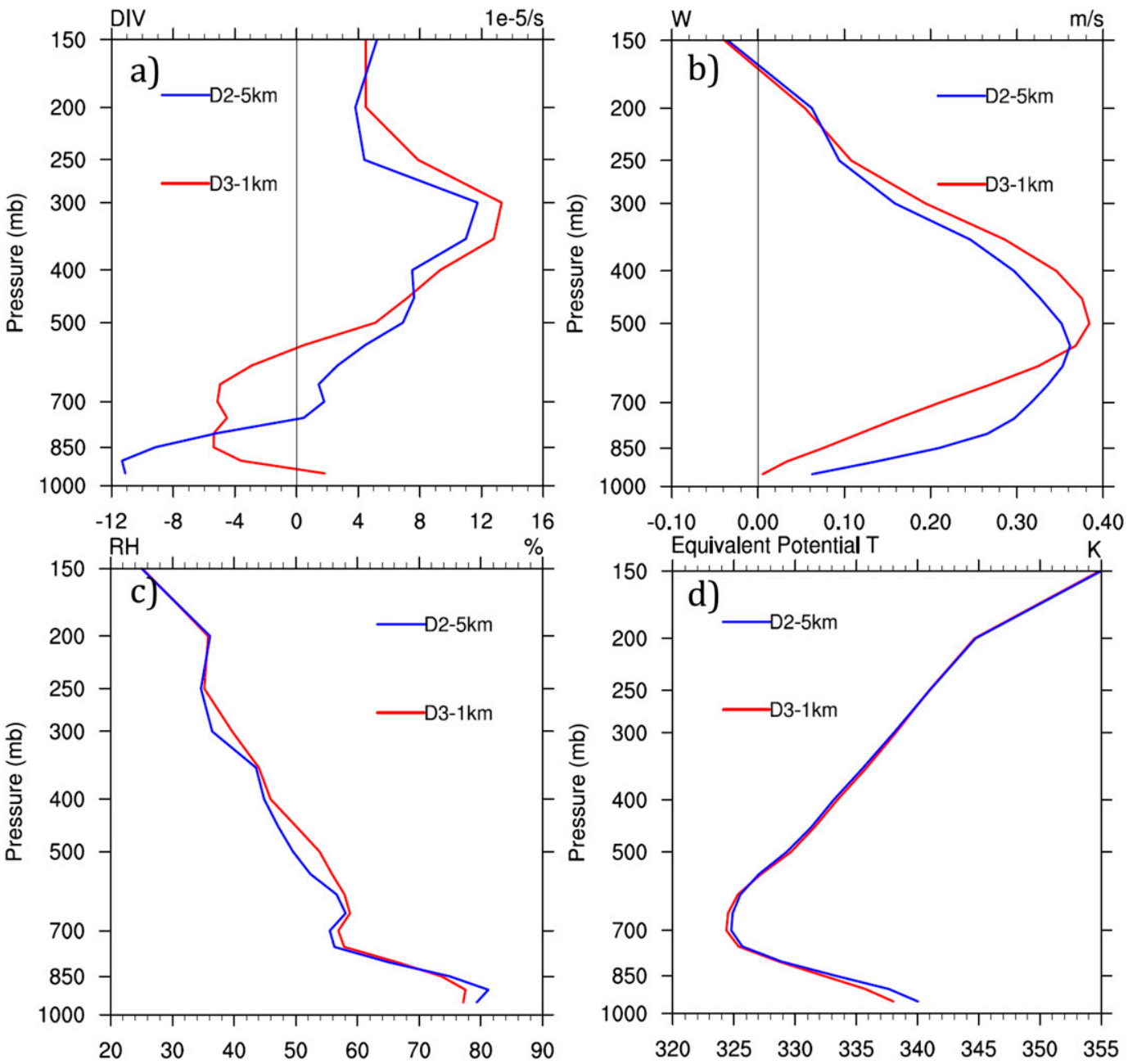

FIG. 8. Vertical profile of (a) divergence $\left(10^{-5} \mathrm{~s}^{-1}\right)$, (b) upward motion $\left(\mathrm{m} \mathrm{s}^{-1}\right)$, (c) relative humidity (\%), and (d) equivalent potential temperature $(\mathrm{K})$ averaged over the Jeddah catchment during rainstorms for the mean of all three cases from D3 (red line) and D2 (blue line).

$33 \mathrm{~mm})$. In general, it is found that D3 has both a larger accumulated rainfall amount and a higher rainfall rate peak value compared with D2 for both the Jeddah station and the catchment, although case 3 is a little different at catchment scale. Therefore, in the Jeddah area, the simulation with higher horizontal grid resolution (e.g., D3) generally has a better capacity in reproducing heavy rainfall, especially for the extreme value.

Figure 8 illustrates the corresponding atmospheric features averaged during the rainstorms for all three cases in D3 and D2, and the average period is identified in Figs. 7e, 7f, S8e, S8f, S8k, and S81 as the whole rainfall process. The vertical profile in Fig. 8 provides some explanation as to why D3 has larger rainfall values compared with D2. For instance, the vertical divergence in Fig. 8a shows that D3 has deeper convergence in the lower troposphere (below $650 \mathrm{hPa}$ ) and larger divergence in the upper troposphere (around $300 \mathrm{hPa}$ ), which suggest a stronger convective activity in the D3 compared with D2. Corresponding to this stronger convection activity, there is a larger and higher upward motion center in $\mathrm{D} 3(500 \mathrm{hPa})$ compared with the one in D2 (around $600 \mathrm{hPa}$; Fig. 8b). In turn, the stronger convective activity and vertical transportation lead to a drier low troposphere (below $750 \mathrm{hPa}$ ) and a wetter middle-to-upper troposphere (from 750 to $250 \mathrm{hPa}$ ) for D3 compared with D2 (Fig. 8c). The vertical profile of equivalent potential temperature (Fig. 8d) shows little difference between D2 and D3. With the equivalent potential temperature decreasing with height, the atmosphere is unstable in the lower troposphere for both D3 and D2, which favors the occurrence of convection. Overall, the stronger deep convective activity and its associated features are the main reasons for the enhancement of heavy rainfall in the simulations around Jeddah area, when downscaling from D2 to D3. The 
TABLE 2. WRF configurations for tests $1-4$.

\begin{tabular}{llll}
\hline \multicolumn{1}{c}{ Cu_physics } & D1 & D2 & D3 \\
\hline Test 1 (Grell-D1) & Grell & No & No \\
Test 2 (KF-D1) & KF & No & No \\
Test 3 (Grell-D1.D2) & Grell & Grell & No \\
Test 4 (KF-D1.D2) & KF & KF & No \\
\hline
\end{tabular}

mechanism related to this behavior is discussed further in section 5 .

\section{c. Impact of cumulus scheme at 5-km-resolution intermediate domain}

Currently, there is no comprehensive guidance on the use of a dedicated cumulus scheme at the intermediate resolutions between approximately 3 and $10 \mathrm{~km}$ in atmospheric models. To explore the most appropriate reproduction of the flash-flood events, we examine the use of the cumulus scheme in D2. Table 2 identifies four test cases that use the same physics combinations (similar to Table 1), except for the cumulus scheme at $5-\mathrm{km}$ resolution. Test 1 and test 2 use the cumulus schemes [Grell and Kain-Fritsch (KF) schemes, respectively] only in the outer domain 1 (hereafter Grell-D1 and KF$D 1$, respectively), while test 3 and test 4 use the cumulus scheme (Grell and KF, respectively) not only in the outer domain, but also in the intermediate domain 2 (hereafter Grell-D1.D2 and KF-D1.D2, respectively). Through comparisons of Grell-D1 with Grell-D1.D2 and KF-D1 with KF-D1.D2, we can explore the impact of the use of cumulus scheme at $5-\mathrm{km}$ resolution in domain 2 for heavy rainfall simulations.

For case 1, the impact of the cumulus scheme on the rainfall is not immediately clear (Fig. 9a) at the Jeddah station for D3, and the simulated accumulated rainfall values agree well with the TRMM and radar data (approximately $15 \mathrm{~mm}$ ). For the rainfall averaged over the Jeddah catchment, the accumulated rainfall is larger in the tests that do not have the explicit cumulus scheme at 5-km resolution (Grell-D1 and KF-D1) compared to those that do (Grell-D1.D2 and KF-D1.D2; see Fig. 9b), especially when compared to the Grell-D1.D2, which has a value around zero (Figs. 9a-c). The difference in accumulated rainfall for Grell-D1 vs Grell-D1.D2 is $17 \mathrm{~mm}$ and for KF-D1 vs KF-D1.D2 is $6 \mathrm{~mm}$. The hourly evolution of rainfall over the Jeddah catchment also shows higher peaks in Grell-D1 and KF-D1 when compared with Grell-D1.D2 and KF-D1.D2, respectively (Fig. 9c). In addition, Grell-D1.D2 and KFD1.D2, with the larger accumulated rainfall value and higher rainfall peaks, agree better with the TRMM and radar data (Figs. 9b,c). The comparisons of the four test runs for case 2 present similar features as those for

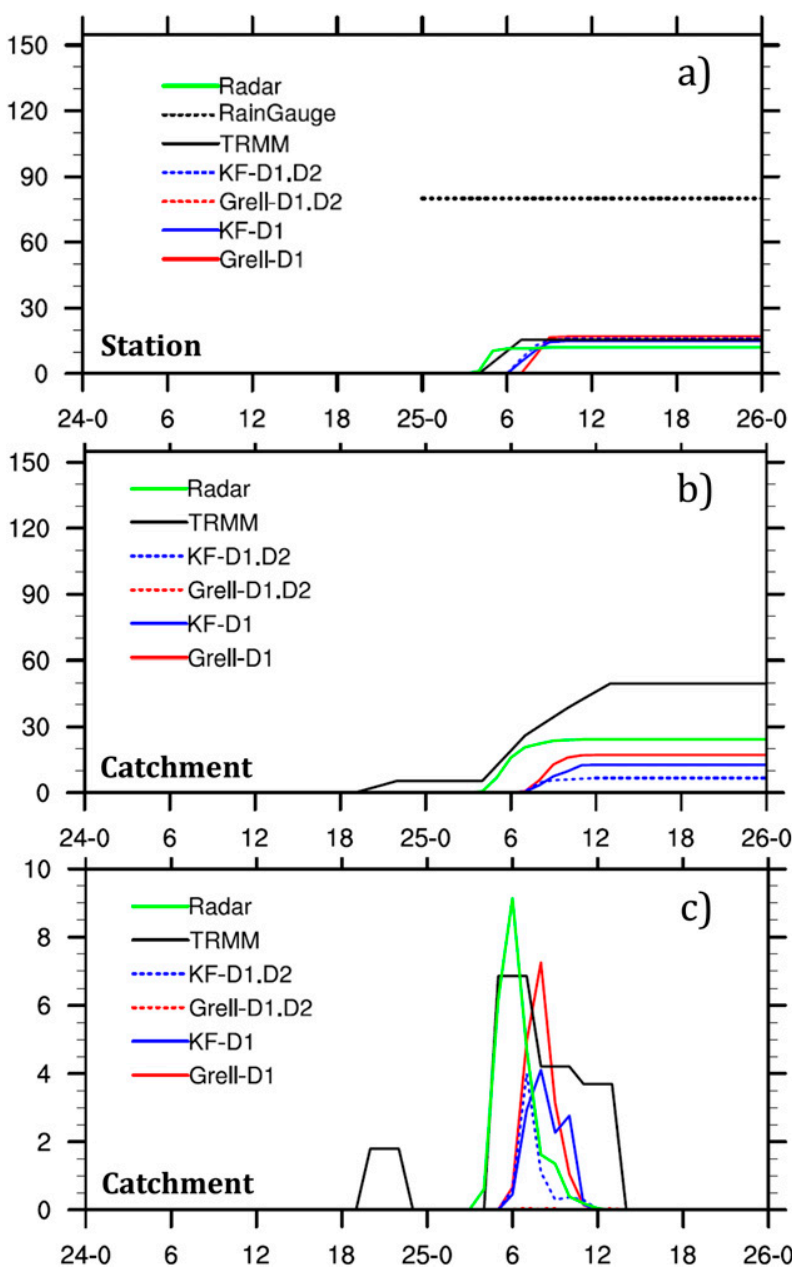

FIG. 9. Time evolution of (a) accumulated rainfall (mm) at Jeddah station and (b) accumulated rainfall $(\mathrm{mm})$ and (c) precipitation rate $\left(\mathrm{mm} \mathrm{h}^{-1}\right)$ averaged over the Jeddah catchment for case 1 from the Taif radar (green line), rain gauge (daily, black dash line), TRMM (black solid solid), KF-D1.D2 (blue dashed line), Grell-D1.D2 (red dashed line), KF-D1 (blue solid line), and Grell-D1(red solid line).

case 1, with even larger rainfall differences (e.g., around $75 \mathrm{~mm}$ in Fig. S9c for Grell-D1 vs Grell-D1.D2). At the Jeddah station, Grell-D1.D2 and KF-D1.D2 are closer to the TRMM data compared to Grell-D1 and KF-D1 (Fig. S9a) but overestimate the rain gauge data. For the catchment, all four test runs overestimate the observations (Figs. S9c,e). Model comparisons for case 3 (Figs. S9b,d,f) also agree with results from cases 1 and 2 . Overall, it is observed that simulated rainfall in the Jeddah region is enhanced if the intermediate $5-\mathrm{km}$ D2 does not use a cumulus scheme (Grell or KF). Also, comparisons between model runs and the observations do not allow for a general statement about the improvement of rainfall simulations according to the use of cumulus scheme. Additionally, we found that the runs using the Grell scheme produce more rainfall than those 

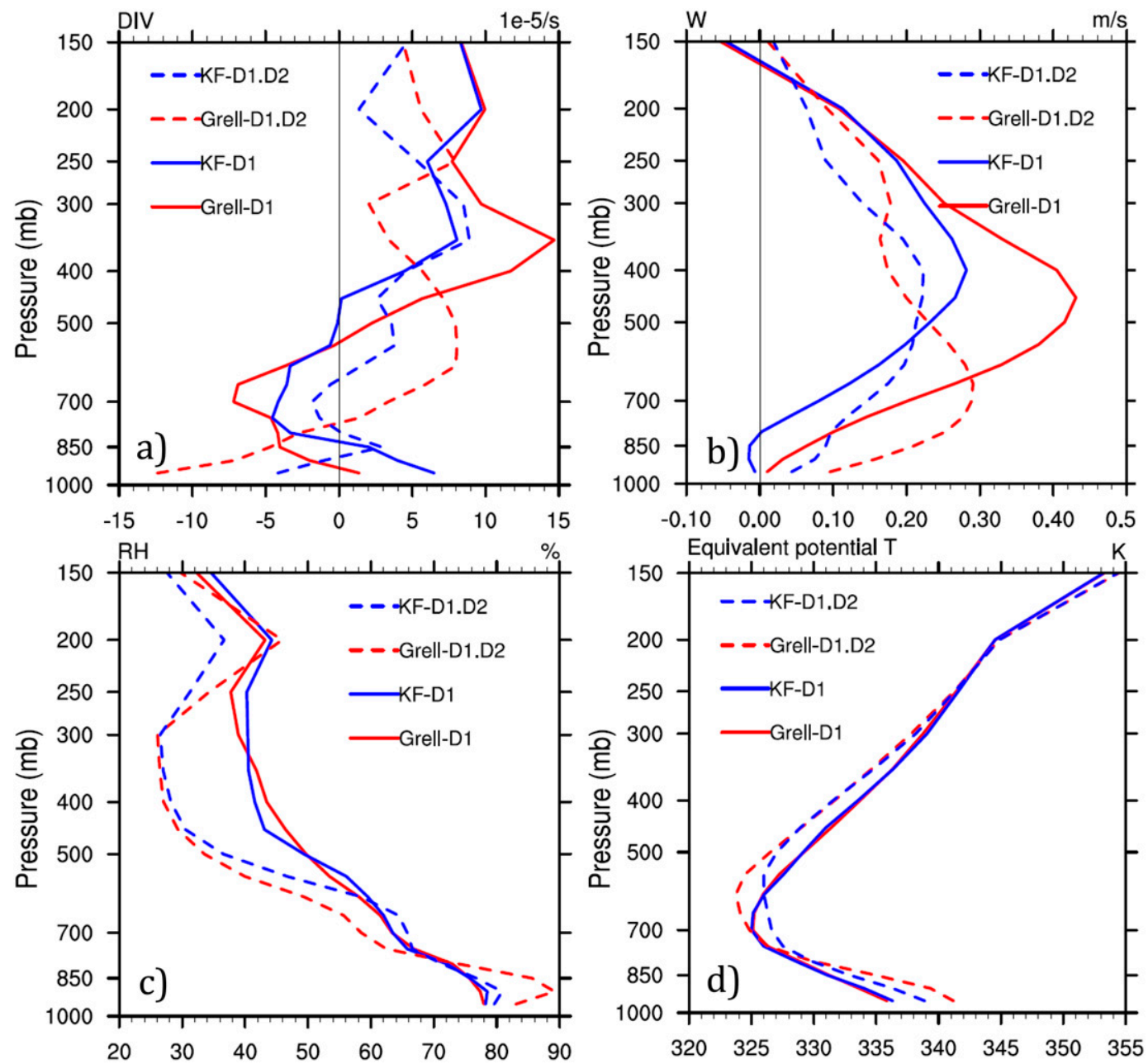

FIG. 10. Vertical profiles of (a) divergence $\left(10^{-5} \mathrm{~s}^{-1}\right)$, (b) upward motion $\left(\mathrm{m} \mathrm{s}^{-1}\right)$, (c) relative humidity (\%), and (d) equivalent potential temperature $(\mathrm{K})$ averaged over the Jeddah catchment during the rainstorms for KF-D1.D2 (blue dashed line), Grell-D1.D2 (red dashed line), KF-D1 (blue solid line), and Grell-D1(red solid line).

using the KF scheme when comparing Grell-D1 with KF-D1, at least in the Jeddah area.

Figure 10 shows the mean vertical profiles of divergence, upward motion, relative humidity, and equivalent potential temperature for all three cases averaged over the Jeddah catchment during the rain events in D3. The vertical profiles of divergence show a deeper convergence in the lowtroposphere and a stronger divergence in the upper troposphere for Grell-D1 and KF-D1 compared with Grell-D1.D2 and KF-D1.D2 (Fig. 10a), respectively, which suggests that more deep convection is simulated in the run without using a cumulus scheme at the $5-\mathrm{km}$ resolution. The corresponding upward motion for Grell-D1 and KF-D1 is stronger than that in Grell-D1.D2 and KF-D1.D2 (see Fig. 10b), respectively, and the associated moisture content in the upper troposphere is also larger in GrellD1 and KF-D1 (see Fig. 10c). For the equivalent potential temperature in the middle-to-upper troposphere (see Fig. 10d), Grell-D1 and KF-D1 are warmer than Grell-D1.D2 and KF-D1.D2, which is consistent with the more moist deep convection and thus the greater latent heating in Grell-D1 and KF-D1. The lower troposphere in Grell-D1 and KF-D1 is cooler than that in Grell-D1.D2 and KF-D1.D2, which may relate to the cooling impacts caused by the "re-evaporation" of more rainfall drops from the deeper convection in Grell-D1 and KF-D1. Overall, the test cases without a cumulus scheme at the intermediate domain (D2) resolution lead to a stronger deep convection with a wetter and warmer environment in the middle-to-upper troposphere of D3, corresponding to a rainfall enhancement, as shown in Fig. 9.

\section{Discussion}

The work presented here seeks to examine the similarity (or not) of initial conditions for three recent Jeddah flash 
floods while investigating the feasibility of using WRF (version 3.5) to achieve realistic simulation of flash-floodproducing rain events. Through development of a multiple nesting approach, the impacts of model simulation at higher resolutions (from 5 to $1 \mathrm{~km}$ ) and the use of a dedicated cumulus scheme at the intermediate $5-\mathrm{km}$ domain are also explored, with the aim to provide improved rainfall simulation, particularly for extreme values. The analysis of all three cases revealed that mesoscale convective systems associated with strong moisture convergence ahead of a trough were the major initial factor for the floodproducing rainfall in the Jeddah area. The related antecedent synoptic features included a cyclone between two anticyclones, a 700-hPa trough, a low-level jet, a moist environment, and strong lower tropospheric convergence. These factors, together with the complex topography surrounding the Jeddah metropolitan area, contributed to the development of flooding.

The WRF Model with one-way nesting was able to represent the heavy precipitation events not only at the station but also for the whole Jeddah catchment, especially regarding the key hydrological characteristics of amount and intensity. Although there is observed temporal and spatial displacement, the movement of the storm track from the northwest to southeast across the Jeddah region was simulated well. Considering the capacity to reproduce extreme rainfall and the related duration of the rain events, the convective processes reproduced by the highresolution convection-permitting model displayed an appropriate moisture budget for a moving mesoscale convective system.

Providing realistic hydrological forcing is a significant step in producing more realistic hydrological simulations of streamflow, particularly in event-based flashflood scenarios. However, the displacement of the rainstorm simulation suggests that the temporal and spatial structure of the simulated mesoscale convective systems in atmospheric models presents a potential roadblock for finescale hydrological simulations. Further investigation of the key physical processes and biases related to initial and boundary conditions may provide insight into a solution for improved representation of the temporal and spatial structure of these events. Even in the case where the spatial fidelity is not matched perfectly, having the capacity to reproduce the intensity, frequency, and duration of such extreme rainfall events represents a major new source of information for water resource planning, security, and management, as well as enhancing responses related to emergency and disaster management.

Although higher-resolution approaches will not solve all scale-related problems, the downscaling method in this paper shows clear advantage in heavy rainfall simulations, especially in the cases of extreme values. Increasing the resolution from 5 to $1 \mathrm{~km}$ combined with the use of a physically representative topography ensures that local convection processes will not have a homogeneous underlying surface when passing over the Jeddah area. Instead, convective systems will be lifted by the increases in topography from west to east (considering the mountains in the east). This topographic lifting contributes to a deeper lower troposphere convergence layer and is correlated to the middle-to-upper troposphere enhancement of moisture upward transport that is shown in Fig. 8, which in turn contributes to the development of deeper convective systems and corresponding changes in the amount and intensity of rainfall. As such, the high horizontal grid resolution (D3) favors the simulation of heavy rainfall, a result that is consistent with some previous studies examining the impact that topography has on heavy rainfall simulations [e.g., $+20 \%$ in Hong and Lee (2009)].

It is well known that heavy rainfall is strongly tied to deep convective activity. As such, an appropriate heavy rainfall simulation depends intimately on the cumulus scheme when one is present. Without a prescribed cumulus scheme, the heavy rainfall simulation is mainly due to resolved convective processes. In our results, the cases without cumulus scheme at the intermediate $5-\mathrm{km}$ domain (D2) resolve stronger mesoscale convective systems with a deeper convergence layer in the low troposphere and a wetter and warmer environment in the middle-to-upper troposphere (Fig. 10) compared to runs using a cumulus scheme. As such, this suggests that the boundary-condition changes (prepared by D2 and used by D3) produced by the use of a cumulus scheme at D2 have a detrimental effect on the vertical profile of the deep convections in D3. Indeed, the model can produce an enhancement on the amount and intensity of precipitation for the runs without a dedicated cumulus scheme at the intermediate 5-km domain (see Fig. 9). Overall, the use of a cumulus parameterization for the intermediate 5-km-resolution domain generally did not provide enhanced model performance for heavy rainfall simulation in the Jeddah area.

An important aspect of this study is the difference between observational datasets. Current rainfall comparison with the model is performed using both point-scale (rain gauge) and grid-scale (satellite and radar) rainfall data. Although they are all observing the same event, they are quite different because of the diversity of measurement techniques, retrieval processes, and resolution. The accumulated rainfall (Figs. S10a-c) from 0000 UTC 24 November to 0000 UTC 26 November for case 1 shows a clear rainstorm along the Red Sea coast with a center around Jeddah from TRMM, ERA-I, and Taif radar datasets. 
However, for the same time period, the intensity, location, and shape of the rainstorm are different in the various observations. The rain gauge reports more than $80 \mathrm{~mm}$ of rainfall in Jeddah, but the rainfall values in TRMM, ERA-I, and radar datasets are small. TRMM and radar datasets indicate approximately $15 \mathrm{~mm}$ of rainfall at the rain gauge station (Fig. 4a), and the value for ERA-I is less than $40 \mathrm{~mm}$ (not shown). Also, TRMM and radar datasets illustrate separated rainfall centers around Jeddah, while ERA-I shows a larger rainstorm with a strong centered peak in the northwest of Jeddah, which influences the rainstorm shape in the WRF simulation (Fig. S10b vs Figs. S10d-f). Overall, more consistent and accurate observational datasets will assist greatly in improving the simulation of these events (McCabe et al. 2008).

\section{Conclusions}

In summary, the three recent Jeddah floods that were analyzed all present the same (or similar) initial synoptic features, described as a moisture convergence zone ahead of a trough. The associated mesoscale convective systems combined with the local topography contribute to the flood-producing rainfall. Localized extreme values of heavy rainfall and the duration of rainstorms within the Jeddah catchment area can be captured reasonably well by a convection-permitting WRF Model, albeit with some displacement of rainstorm events. Through the comparison between domains 2 and 3, it is found that higherresolution topography in the WRF Model over the Jeddah area generally contributes to an enhancement of local deep convective systems and the related heavy rainfall intensities. Compared to the intermediate domain $2(5-\mathrm{km}$ resolution) with a cumulus scheme, the one without a cumulus scheme shows positive impacts on domain 3's deep convective activity, which leads to a larger localized volume of rainfall.

It is important to note that the studies presented here are based on only three recent cases for the Jeddah area. Further cases, both locally and regionally, along with an examination of different mechanism and WRF physics combinations, are required to propose a reasonable physical description for the simulation of heavy rainfall events. Likewise, in the absence of dense networks and reliable sources of in situ data, additional metrics of performance need to be explored, relying more on complementary remote sensing datasets and other sources of related information.

Acknowledgments. We thank Dr. Abdou A. Abouelmagd and Dr. Weichun Tao for providing Jeddah shape files used in this analysis. The assistance from
Dr. Basit A. Khan on the WRF simulations is greatly appreciated. This work was supported by the Earth System Observation and Modelling (ESOM) group and the Physical Sciences and Engineering Division at King Abdullah University of Science and Technology (KAUST), Saudi Arabia. For computer time, this research used the resources of the Supercomputing Lab at KAUST, Saudi Arabia.

\section{REFERENCES}

Al-Khalaf, A., and H. A. Basset, 2013: Diagnostic study of a severe thunderstorm over Jeddah. Atmos. Climate Sci., 3, 150-164, doi:10.4236/acs.2013.31017.

Almazroui, M., 2011: Sensitivity of a regional climate model ( $\mathrm{RegCM} 3)$ on the simulation of high intensity rainfall events over the Arabian Peninsula and around Jeddah (Saudi Arabia). Theor. Appl. Climatol., 104, 261-276, doi:10.1007/ s00704-010-0387-3.

Alpert, P., I. Osetinsky, B. Ziv, and H. Shafir, 2004: Semi-objective classification for daily synoptic systems: Application to the eastern Mediterranean climate change. Int. J. Climatol., 24, 1001-1011, doi:10.1002/joc.1036.

Al Saud, M., 2010: Assessment of flood hazard of Jeddah area 2009, Saudi Arabia. J. Water Resour. Prot., 2, 839-847, doi:10.4236/ jwarp.2010.29099.

Anquetin, S., and Coauthors, 2005: The 8 and 9 September 2002 flash flood event in France: An intercomparison of operational and research meteorological models. Nat. Hazards Earth Syst. Sci., 5, 741-754, doi:10.5194/nhess-5-741-2005.

Cardoso, R. M., P. M. M. Soares, P. M. A. Miranda, and M. BeloPereira, 2013: WRF high resolution simulation of Iberian mean and extreme precipitation climate. Int. J. Climatol., 33, 2591-2608, doi:10.1002/joc.3616.

Cools, J., and Coauthors, 2012: An early warning system for flash floods in hyper-arid Egypt. Nat. Hazards Earth Syst. Sci., 12, 443-457, doi:10.5194/nhess-12-443-2012.

Davolio, S., D. Mastrangelo, M. M. Miglietta, O. Drofa, A. Buzzi, and P. Malguzzi, 2009: High resolution simulations of a flash flood near Venice. Nat. Hazards Earth Syst. Sci., 9, 1671-1678, doi:10.5194/nhess-9-1671-2009.

Dee, D. P., and Coauthors, 2011: The ERA-Interim reanalysis: Configuration and performance of the data assimilation system. Quart. J. Roy. Meteor. Soc., 137, 553-597, doi:10.1002/ qj. 828.

De Vries, A. J., E. Tyrlis, D. Edry, S. O. Krichak, B. Steil, and J. Lelieveld, 2013: Extreme precipitation events in the Middle East: Dynamics of the active Red Sea trough. J. Geophys. Res. Atmos., 118, 7087-7108, doi:10.1002/jgrd.50569.

El Kenawy, A. M., M. F. McCabe, G. L. Stenchikov, and J. Raj, 2014: Multi-decadal classification of synoptic weather types, observed trends and links to rainfall characteristics over Saudi Arabia. Front. Environ. Sci., 2, 37, doi:10.3389/ fenvs.2014.00037.

Evans, J. P., and M. F. McCabe, 2010: Regional climate simulation over Australia's Murray-Darling basin: A multitemporal assessment. J. Geophys. Res., 115, D14114, doi:10.1029/ 2010JD013816.

, and - 2013: Effect of model resolution on a regional climate model simulation over southeast Australia. Climate Res., 56, 131-145, doi:10.3354/cr01151. 
Gao, W., and C.-H. Sui, 2013: A modeling analysis of rainfall and water cycle by the cloud-resolving WRF Model over the western North Pacific. Adv. Atmos. Sci., 30, 1695-1711, doi:10.1007/ s00376-013-2288-8.

Grell, G. A., 1993: Prognostic evaluation of assumptions used by cumulus parameterizations. Mon. Wea. Rev., 121, 764-787, doi:10.1175/1520-0493(1993)121<0764:PEOAUB>2.0.CO;2. , and D. Devenyi, 2002: A generalized approach to parameterizing convection combining ensemble and data assimilation techniques. Geophys. Res. Lett., 29, 1693, doi:10.1029/ 2002GL015311.

Haggag, M., and H. El-Badry, 2013: Mesoscale numerical study of quasi-stationary convective system over Jeddah in November 2009. Atmos. Climate Sci., 3, 73-86, doi:10.4236/ acs.2013.31010.

Heikkilä, U., A. Sandvik, and A. Sorteberg, 2011: Dynamical downscaling of ERA-40 in complex terrain using the WRF regional climate model. Climate Dyn., 37, 1551-1564, doi:10.1007/ s00382-010-0928-6.

Hong, S. Y., and J. W. Lee, 2009: Assessment of the WRF Model in reproducing a flash-flood heavy rainfall event over Korea. Atmos. Res., 93, 818-831, doi:10.1016/j.atmosres.2009.03.015.

Huffman, G. J., and Coauthors, 2007: The TRMM Multisatellite Precipitation Analysis (TMPA): Quasi-global, multiyear, combined-sensor precipitation estimates at fine scales. $J$. Hydrometeor., 8, 38-55, doi:10.1175/JHM560.1.

Iacono, M. J., J. S. Delamere, E. J. Mlawer, M. W. Shephard, S. A. Clough, and W. D. Collins, 2008: Radiative forcing by longlived greenhouse gases: Calculations with the AER radiative transfer models. J. Geophys. Res., 113, D13103, doi:10.1029/ 2008JD009944.

Janjić, Z. I., 1994: The step-mountain eta coordinate model: Further developments of the convection, viscous sublayer, and turbulence closure schemes. Mon. Wea. Rev., 122, 927-945, doi:10.1175/ 1520-0493(1994)122<0927:TSMECM >2.0.CO;2.

- 2001: Nonsingular implementation of the Mellor-Yamada Level 2.5 Scheme in the NCEP Meso model. NCEP Office Note 437, 61 pp. [Available online at www.emc.ncep.noaa.gov/ officenotes/newernotes/on437.pdf.]

Kain, J. S., 2004: The Kain-Fritsch convective parameterization: An update. J. Appl. Meteor., 43, 170-181, doi:10.1175/ 1520-0450(2004)043<0170:TKCPAU > 2.0.CO;2.

-, and J. M. Fritsch, 1990: A one-dimensional entraining/ detraining plume model and its application in convective parameterization. J. Atmos. Sci., 47, 2784-2802, doi:10.1175/ 1520-0469(1990)047<2784:AODEPM>2.0.CO;2.

Kopparla, P., E. M. Fischer, C. Hannay, and R. Knutti, 2013: Improved simulation of extreme precipitation in a high-resolution atmosphere model. Geophys. Res. Lett., 40, 5803-5808, doi:10.1002/ 2013GL057866.

Kucera, P. A., and Coauthors, 2010: Features of the Weather Modification Assessment Project in the southwest region of Saudi Arabia. J. Wea. Modif., 42, 78-103.

Lin, Y.-L., R. D. Farley, and H. D. Orville, 1983: Bulk parameterization of the snow field in a cloud model. J. Climate Appl. Meteor., 22, 1065-1092, doi:10.1175/1520-0450(1983)022<1065: BPOTSF $>2.0 . \mathrm{CO} ; 2$.

McCabe, M., E. F. Wood, R. Wójcik, M. Pan, J. Sheffield, H. Gao, and $\mathrm{H}$. Su, 2008: Hydrological consistency using multi-sensor remote sensing data for water and energy cycle studies. Remote Sens. Environ., 112, 430-444, doi:10.1016/j.rse.2007.03.027.

Miguez-Macho, G., G. L. Stenchikov, and A. Robock, 2004: Spectral nudging to eliminate the effects of domain position and geometry in regional climate model simulations. J. Geophys. Res., 109, D13104, doi:10.1029/2003JD004495.

Rutledge, S. A., and P. V. Hobbs, 1984: The mesoscale and microscale structure and organization of clouds and precipitation in midlatitude cyclones. XII: A diagnostic modeling study of precipitation development in narrow cold-frontal rainbands. J. Atmos. Sci., 41, 2949-2972, doi:10.1175/1520-0469(1984)041<2949: TMAMSA $>2.0 . \mathrm{CO} ; 2$.

Tewari, M., and Coauthors, 2004: Implementation and verification of the unified NOAH land surface model in the WRF Model. Preprints, 20th Conf. on Weather Analysis and Forecasting/ 16th Conf. on Numerical Weather Prediction, Seattle, WA, Amer. Meteor. Soc., 14.2a. [Available online at https://ams. confex.com/ams/84Annual/techprogram/paper_69061.htm.]

Tsvieli, Y., and A. Zangvil, 2005: Synoptic climatological analysis of 'wet' and 'dry' Red Sea troughs over Israel. Int. J. Climatol., 25, 1997-2015, doi:10.1002/joc. 1232.

Xie, B., and F. Zhang, 2012: Impacts of typhoon track and island topography on the heavy rainfalls in Taiwan associated with Morakot (2009). Mon. Wea. Rev., 140, 3379-3394, doi:10.1175/ MWR-D-11-00240.1.

Zhang, Y., V. Dulière, P. W. Mote, and E. P. Salathé, 2009: Evaluation of WRF and HadRM mesoscale climate simulations over the U.S. Pacific Northwest. J. Climate, 22, 5511-5526, doi:10.1175/2009JCLI2875.1. 